Античная древность и средние века. Т. 48. С. 106-116

УДК $821.14+82-343.5$

DOI 10.15826/adsv.2020.48.007

\author{
Ю. Б. Мантова \\ Московский государственный университет им. М. В. Ломоносова \\ Москва, Россия

\section{СВЕТСКИЙ ЧИНОВНИК КАК АГИОГРАФ: НИКИТА МАГИСТР И ЖИТИЕ ФЕОКТИСТЫ ЛЕСБОССКОЙ}

Светские и военные чиновники, члены императорской семьи, сами императоры и императрицы являются привычными персонажами византийских агиографических произведений. Тем не менее, довольно редко происходит, когда один из этих чиновников становится автором житийного текста. Житие Феоктисты Лесбосской, написанное в X в. Никитой Магистром, предоставляет нам уникальную возможность взглянуть на взаимоотношения святых и власти не только во внутреннем пространстве текста, но и посредством внешнего сопоставления - автор и его произведение. В статье рассматривается, как Никита Магистр описывает свое отношение к героям, а также делаются предположения о том, что побудило его обратиться к агиографическому жанру. Возможно, текст был составлен для демонстрации Константину VII выдающихся способностей автора, который стремился художественными средствами донести до императора идею о раскаянии в былом тщеславии и таким образом просил о прощении и возможности вернуться из ссылки в Константинополь. Для достижения своей цели Никита Магистр выстраивает образы своих героев определенным образом. Смиренность монаха Симеона представляется как высшая человеческая добродетель, а проступок безымянного охотника, укравшего руку почившей Феоктисты, заслуживает понимания и прощения, поскольку человеку свойственно ошибаться.

Ключевые слова: византийская агиография; жития святых; Никита Магистр; Феоктиста Лесбосская

Цитирование: Мантова Ю. Б. Светский чиновник как агиограф: Никита Магистр и Житие Феоктисты Лесбосской. DOI 10.15826/adsv.2020.48.007 // Античная древность и средние века. 2020. Т. 48. С. 106-116.

Поступила в редакиию 08.08.2020

Принята к печати 15.10.2020

(C) Мантова Ю. Б., 2020 
Светский чиновник как агиограф

\author{
Yulia B. Mantova \\ M. V. Lomonosov Moscow State University \\ Moscow, Russia
}

\title{
SECULAR OFFICIAL AS A HAGIOGRAPHER: NIKETAS MAGISTROS AND THE LIFE OF THEOKTISTE OF LESBOS
}

Middle Byzantine hagiography abounds with the episodes representing the interaction of saint protagonists with the authorities. Apart of communicating to emperors and empresses, they also deal with the wide range of military and civil bureaucracy representatives in various circumstances. In contrast, it is quite a rare instance when a state official created a hagiographical narrative. The tenth-century Life of Theoktiste of Lesbos written by Niketas Magistros provides a unique opportunity to explore the relationship between saints and power not through the inner text space only, but through the outer juxtaposition as well: the text vs the author. The paper focuses on how the author describes his holy heroes and what made Niketas turn to hagiography. Presumably, the text was created to demonstrate to Constantine VII the outstanding abilities of the author who wished to convey to the emperor the idea on his repentance regarding his former mistakes and to plea the emperor to get the permission to return to Constantinople. In order to achieve this aim, Niketas Magistros builds up the images of his characters in a special way. Monk Symeon's humbleness is represented as the highest human virtue, though the unnamed hunter's misconduct who tried to steal the deceased Theoktiste's relics deserves understanding and forgiveness for it is human not to comply with the prudence and piousness.

Keywords: Byzantine hagiography; lives of saints; Niketas Magistros; Theoktiste of Lesbos

For citation: Mantova Yu. B. (2020). Svetskii chinovnik kak agiograf: Nikita Magistr i Zhitie Feoktisty Lesbosskoi [Secular Official as a Hagiographer: Niketas Magistros and the Life of Theoktiste of Lesbos]. Antichnaya drevnost'i srednie veka, 48, 106-116. doi: 10.15826/adsv.2020.48.007

Submitted: 08.08.2020

Accepted: 15.10 .2020

Житие Феоктисты, составленное Никитой Магистром в X в., уже не одно десятилетие является предметом особого внимания исследователей ${ }^{1}$. Около тридцати лет назад в научном сообществе разгорелась полемика между двумя выдающимися византинистами - Б. Флюзе-

\footnotetext{
${ }^{1}$ Vita S. Theoctistae de insula Lesbo // Acta Sanctorum. Bruxelles, 1925. T. 4. Novembris.
} Р. 224-233 (далее - Vita). 
Ю. Б. Мантова

ном и А. П. Кажданом. И если последний говорил, что традиционная религиозная составляющая в этом повествовании не вызывает никаких сомнений르, то Флюзен считал, что данный текст - это пародия на каноническое житие, высмеивающая привычные приемы и топосы ${ }^{3}$. Такая крайняя точка зрения не была принята, поскольку текст почти без изменений был включен в собрание Симеона Метафраста. В то же время и позиция Каждана была пересмотрена. Сегодня исследователи сошлись во мнении, что автор действительно отошел от многих канонов житийного жанра, довольно свободно экспериментировал с формой и наполнил повествование античными аллюзиями, поскольку ориентировался на изысканную образованную публику, которая должна была получить удовольствие от такой литературной игры В 2018 г. Кристиан Хёгель опубликовал статью, где продолжил исследование литературной ткани произведения, а также сделал несколько важных выводов о построении особой драматургии и тематике повествования 5 . Он высказал мнение, что эстетические установки Никиты Магистра, воспевание красоты произведений, искусства и красоты слова является одной главных тем всего жития. Кроме того, Хёгель обратился к исторической стороне вопроса. Он проанализировал данные об обстоятельствах жизни Никиты и сделал предположение, что текст был написан гораздо позднее, нежели 913-919 гг., как считал один из первых исследователей наследия Никиты Магистра Л. Вестеринк ${ }^{6}$. Хёгель обратил внимание на замечание Никиты о том, что смерть Льва VI (886-912) ознаменовала конец благополучия для ромеев, и интерпретировал этот фрагмент как лесть в адрес наконец-то приступившего к самостоятельному правлению сына Льва VI - Константина VII (913 (фактически с 945)-959). Действительно, в годы царствования Романа I Лакапина (920-944) такое замечание звучало бы слишком резко и вряд ли могло быть высказано Никитой, одним из верных соратников Романа по крайней мере до 927 г., когда он был сослан из-за обвинения в организации заговора против царствовавшего

\footnotetext{
${ }^{2}$ Kazhdan A. Hagiographical Notes 9. The Hunter or the Harlot // BZ. 1985. T. 78. S. 49-55.

${ }^{3}$ Flusin B. L'Hagiographie monastique à Byzance au IXe et au Xe siècle // Revue Bénédictine. 1993. Vol. 103. P. 31-50.

${ }^{4}$ Многочисленные литературные параллели и аллюзии на античные произведения подробно изучены, см.: Jazdzewska K. Hagiographic Invention and Imitation: Niketas' Life of Theoktiste and Its Literary Models // GRBS. 2009. Vol. 49. P. 257-279; Nilsson I. The Same Story, but Another. A Reappraisal of Literary Imitation in Byzantium // Imitatio - Aemulatio Variatio. Akten des internationalen wissenschaftlichen Symposions zur byzantinischen Sprache und Literatur / Hrsg. von A. Rhoby, E.Schiffer. Wien, 2010. S. 195-208.

${ }^{5}$ Høgel C. Beauty, Knowledge and Gain in the Life of Theoktiste // Byz. 2018. T. 88. P. 219-236.

${ }^{6}$ Westerink L. G. Nicétas Magistros. Lettres d'un exilé (928-946) (Le Monde Byzantin). Paris, 1973.
} 


\section{Светский чиновник как агиографр}

тогда императора7 ${ }^{7}$ Далее Хёгель провел параллель между созданием текста жития и письмом № 31 из эпистолярного наследия Никиты, которое адресовано императору Константину VII и содержит просьбу о помиловании и разрешении вернуться из ссылки в столицу. Письмо, очевидно, датируется временем после 945 г., и Хёгель предположил, что Никита Магистр дополнил свое прошение великолепным по качеству текстом, который был призван продемонстрировать выдающиеся способности и большой опыт ссыльного чиновника. Таким образом, по мнению Хёгеля, Житие Феоктисты было написано для того, чтобы повлиять на императора и доставить автору желанную награду - разрешение вернуться на государственную службу в Константинополь.

Несмотря на такую богатую историю изучения текста, все еще остаются некоторые аспекты, которые не были рассмотрены в научной литературе. В частности, этот источник представляется интересным с точки зрения репрезентации отношений между святыми и властью, поскольку автор принадлежит миру светской элиты империи и от первого лица описывает свой опыт столкновения с проявлением святости.

\section{Святые и власть в средневизантийской агиографии}

Обширный житийный корпус, созданный в средневизантийский период, отражает довольно богатую палитру взаимоотношений между святыми и представителями власти. Новая эпоха сформировала новый тип святого и, соответственно, новый тип протагониста житийного произведения. Это человек, который живет в столице или большом городе и активно участвует в социально-политических событиях. Таким образом, неудивительно, что целый мир бурной политической жизни хлынул на страницы житий. Однако мы всегда должны учитывать, что исторические события и коллизии, описанные в агиографических текстах, отражаются в этих источниках особым образом. Большое влияние имеют и особенности жанра, и идеологическая ориентация автора. Последнее, впрочем, в полной мере характерно и для историографических произведений. Таким образом, в данной статье предметом нашего рассмотрения является внутренняя, имманентная тексту репрезентация проблемы взаимоотношения святых и представителя светской власти.

С одной стороны, множество житий представляют традиционный расклад сил. В тех случаях, когда власть очевидным образом препятствует исповеданию заветов веры, святые часто выступают как антагонисты этой самой власти, открыто осуждая и чиновников, и императоров. Особенно это характерно для многих текстов, отражающих колли-

\footnotetext{
${ }^{7}$ Niketas, Personenkennziffer 25740 // Prosopographie der mittelbyzantinischen Zeit / Hrsg. von R.-J. Lilie, C. Ludwig, T. Pratsch, B. Zielke. Berlin ; Boston, 2013.
} 
Ю. Б. Мантова

зии иконоборческого конфликта. Яркими примерами являются жития наиболее активного и радикального борца с иконоборчеством Феодора Студита (BHG 1754-1755), житие Никиты Мидикийского, составленное его учеником Феостириктом (BHG 1341), и др. Протагонисты этих повествований представлены как люди с несокрушимой волей, которые не боятся вступить в открытый конфликт с властью и готовы твердо стоять на своих позициях до последнего, несмотря на угрозу ссылки, пыток или даже смерти. Императоры-иконоборцы в подобных текстах традиционно описываются как воплощение зла и насилия, а также как еретики, находящиеся под влиянием Сатаны.

С другой стороны, до нас дошли тексты, которые отражают те же самые сюжеты с определенными нюансами. Императоры могут быть представлены более умеренно, в то время как и сами святые ведут себя более осторожно и сдержанно по отношению к императору. Вспомним, например, Повесть о прощении императора Феофила (BHG 1732-1734). Политическая ангажированность данного источника не вызывает никаких сомнений. Очевидно, что он напрямую отражает стремление светской власти сгладить неудобную ситуацию, когда последовательный и жесткий иконоборец Феофил превратился вдруг из тирана в благочестивого православного христианина. Также агиографы могут сообщать нам и о сомнениях, терзающих героев, и о кардинальном изменении их взглядов. Довольно необычным образом сюжет с обращением Феофила представлен в Житии Давида, Симеона и Георгия (BHG 494). Сначала, когда императрица Феодора просит Симеона даровать Феофилу посмертное прощение, святой отказывается это сделать, что воспринимается читателем как совершенно ожидаемый и закономерный поступок. Однако вскоре Симеон изменяет свое решение и уступает императрице и ее приближенным, что, в свою очередь, выглядит довольно неожиданно. Кроме того, складывается впечатление, что это представлялось не совсем приемлемым и самому агиографу, поскольку он пускается в пространные размышления о причинах, побудивших Симеона так поступить. Нам сообщается, что это произошло после размышлений Симеона о будущем раздираемой противоречиями церкви. В конце концов, он приходит к выводу, что интересы церкви важнее, чем его личное отношение к проблеме 8

Наконец, среди средневизантийских агиографических текстов имеются и такие, где дистанции между святым и властью не существует вовсе. Мы имеем в виду жития императриц Ирины (BHG 2205) и Феодоры (BHG 1731). Причисление обеих царственных дам к лику святых несомненно обусловлено политическими причинами и основано на их дея-

${ }_{8}^{8}$ Acta graeca Ss. Davidis, Symeonis et Georgii / ed. J. van den Gheyn // AnBoll. 1899. Vol. 18. P. 245-246. 


\section{Светский чиновник как агиографр}

тельности по восстановлению иконопочитания. Тем не менее, эти жития, по сути являющиеся императорскими панегириками, формально тоже принадлежат агиографическому канону и могут приниматься в расчет.

Тем не менее, если мы посмотрим на множество таких совершенно разных текстов, все они будут обладать одним общим качеством: автор жития всегда принадлежит миру святого. Как правило, это или монах, или ученик, или просто близкий человек, т. е. нарратив всегда построен вокруг святого, а представители власти описываются как люди из другого мира. И вот в этом отношении житие Феоктисты является уникальным примером, поскольку в центре этого повествования стоит сам автор, который не был учеником святой и не принадлежал монашеской среде. По крайней мере, очевидно, что даже если текст был составлен после ссылки и возможного пострижения Никиты, он выстраивает совершенно однозначную саморепрезентацию. Перед нами предстает образ императорского чиновника, представителя элиты, который сталкивается в ходе своих государственных дел с проявлением святости и чудесами. Таким образом, этот текст предоставляет нам необычную возможность с иного ракурса посмотреть на то, как в агиографии представляются взаимоотношения между святыми и властью, а именно, узнать, что пишут сами эти чиновники о святых людях, с которыми им посчастливилось соприкоснуться.

\section{Никита Магистр о своем отношении к героям}

В первую очередь, необходимо отметить невероятно высокий уровень авторского присутствия в повествовании. Сразу же после вступления Никита начинает рассказывать об обстоятельствах, которые привели его на остров Парос. Он упоминает о том, что был послан с государственной миссией, и, очевидно, считает это обстоятельство достойным того, чтобы стать завязкой для всей истории. Он не только говорит, зачем именно направлялся на Крит, и упоминает имя своего спутника, но и подтрунивает над ним, называя его самым выдающимся военачальником, «...командующим дромом и всем флотом и, по правде

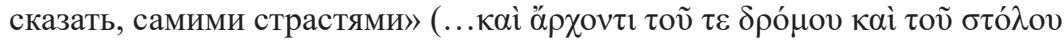

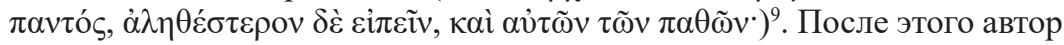
рассказывает об их прогулке по острову, подробно описывает обнаруженный там древний храм и свою встречу с отшельником Симеоном, который позднее поведает ему историю главной героини, услышанную им, в свою очередь, от некоего безымянного охотника. Оценивая фрагмент, где Никита говорит о встреченном им монахе, мы должны признать, что нам не следует искать портрет какого-то конкретного челове-

\footnotetext{
${ }^{9}$ Vita... Р. 225. Здесь и далее перевод автора.
} 
Ю. Б. Мантова

ка, ясно, что речь идет о литературном персонаже, а диалоги выстроены автором. Такая позиция поддерживается и речевой характеристикой этого героя. Мы видим, что речь его совершенно безупречна, так же как, впрочем, и речь всех остальных рассказчиков - безымянного охотника и самой Феоктисты. Так, например, охотник цитирует Фукидида ${ }^{10}$, а длину кабаньих бивней обозначает при помощи гомеровского прила-

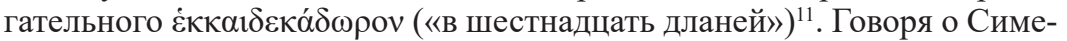
оне, автор подчеркивает его простоту, безыскусность и неподверженность мирским страстям. Вот что отвечает монах, когда Никита спрашивает его в момент встречи, кто он:

Об отечестве и роде моем, и обо всем другом, чем так превозносятся жители городов, мне нечего сказать. Ибо ничто преходящее и ничто из того, что заботит живущих в миру, мне немило. Господь - мой отец и владыка, для Него одного я существую и живу, для него единственного я и обретаюсь в этой пустыни, претерпевая более тридцати лет. Имя же мое - Симеон, чином я смиренный монах, иерей, служитель и отправитель святых и животворящих бескровных таинств ${ }^{12}$.

После таких слов, вложенных в уста Симеона, автор вторит им уже от первого лица, чем ясно демонстрирует свое видение относительно истинного величия человека:

Мы же поразились его благочестию и словам, и облику, и облачению, и аскезе, и особенно тому, что был он служителем Божьим и, припав к его ногам, просили благословения и прощения в судный [день $]^{13}$.

И вот он взял меня за правую руку и пожал ее так, словно уже стал моим другом, потому как к этому его расположила простота его. Ибо души великих мужей, соприкасаясь с благим, стремятся преобразиться по его образу и, будучи причастными к первому из благ, сами становятся совершенно благими, чистыми, простыми, отрешенными от всего мирского; так же и этот старец, такой славный и добрый, в своей простоте казался одним из нас ${ }^{14}$.

После просьбы путников о благословении Симеон предсказывает им удачное дальнейшее плавание и исполнение императорской миссии, что является традиционным мотивом для житийной литературы. Многие святые, обладая особым духовным зрением, могут предвидеть бу-

\footnotetext{
${ }^{10}$ Vita... P. 228.

${ }^{11}$ Ibid. P. 229.

${ }^{12}$ Ibid. P. 226.

${ }^{13}$ Ibid.

${ }^{14}$ Ibid. P. 227.
} 


\section{Светский чиновник как агиографр}

дущее, чем помогают государственным людям принимать правильные решения относительно их карьеры в тех или иных обстоятельствах.

Кроме того, Никита подчеркивает свое благоговейное отношение к старцу и преклонение перед его смирением постоянным употреблени-

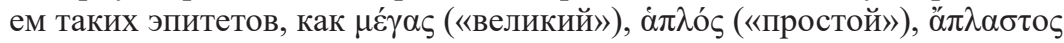

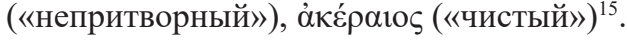

Ясно, что такая характеристика героя прямо противоположна описанию блестящего Гимерия, данному в самом начале истории. Представляется, что Никита противопоставляет двух этих персонажей, чтобы подчеркнуть, в чем именно состоит настоящее достоинство человека. Это особенно важно, если мы вспомним реальную судьбу Гимерия, которая сложилась очень печально. Его блистательная карьера разрушилась в одночасье после неудачи кампании 911 г. Он был сослан и умер шесть месяцев спустя.

В связи с данными наблюдениями интересно вспомнить идею Хёгеля о том, что весь текст был написан с целью воздействия на императора. Если исходить из такого целеполагания, то вероятно, что, постоянно подчеркивая смиренность Симеона как высшую человеческую благодетель, автор пытался донести до императора свою собственную попытку оправдаться, доказать ему, что нынешний Никита Магистр раскаялся в своем былом тщеславии и осознал свои ошибки. Особенно впечатляюще выглядит в таком свете объяснение охотника, композиционного двойника автора, почему он совершил бесчинство - похитил руку почившей Феоктисты. Довольно многословно и сложно описывая свой ход мыслей, он ссылается на собственное невежество, на то, что, как ему казалось, он совершает свою кражу во имя веры, а также замечает, что человеку вообще сложно следовать благоразумию. Причем эта мысль облечена в изысканную художественную форму, обыгрывающую его род занятий: «... поступать благоразумно - трудноу-


автор транслирует свое собственное раскаяние в ошибках молодости и уверения в его настоящей благонадежности.

Размышляя о том, какие особенности репрезентации отношения автора к герою можно счесть нетипичными, мы обратились к версии жития Феоктисты, созданной Симеоном Метафрастом, чтобы проследить, изменил ли он что-то, касающееся нашей темы ${ }^{17}$. Редактура его была совсем незначительна, но есть несколько важных моментов.


дурными нравами») употребляется и у Платона (Respublica, 409a).

${ }^{16}$ Vita... P. 230.

${ }^{17}$ Версия жития, созданная Метафрастом, размещена в критическом аппарате к изданию оригинального текста.
} 


\section{Ю. Б. Мантова}

В первую очередь надо отметить, что переписан проэмий и заключение, о чем мы подробнее скажем ниже. Кроме того, примечательно, что в ходе основного повествования Метафраст систематически убира-

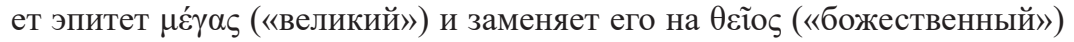

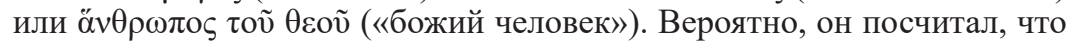
в данном случае такой эпитет не очень соответствует безвестному отшельнику и награждает его более скромным прозванием.

Второе изменение касается эпизода, когда монах предсказывает путешественникам успешный исход их предприятия. Оригинальный автор подчеркивает, что отшельник был совершенно безыскусен и просто искренне поделился с ними своим тайным знанием о будущем. Симеон Метафраст же вставляет собственный комментарий и сообщает, что дав истинное предсказание, пустынник явил всем, что простота и неотесанность, о какой говорилось ранее, была ненастоящей, но он лишь притворялся таковым по причине своего смирения ${ }^{18}$. В этом смысле Метафраст представил образ монаха в более каноническом виде, в то время как Никита определенно делал все наоборот, пытаясь добавить в характер больше живости и отойти от топоса.

Однако, несмотря на поток восхвалений в адрес и монаха, и самой святой, все же невозможно отвлечься от истинного главного героя - от автора, поскольку именно эта фигура стоит в центре всего повествования. Более того, он эксплицитно пишет о том, что монах нуждался в нем, в его помощи, так как в конце разговора Симеон просит об одолжении: записать всю эту историю. Автор дает обещание и начинает расспрашивать о деталях, необходимых для выполнения задания, на что отшельник искренне отвечает, что он и сам не знает многого из того, что следовало бы включить в повествование о святой ${ }^{19}$. По нашему мнению, автор здесь выявляет особую взаимную зависимость интересов обеих сторон. Такое наблюдение полностью отвечает основной мысли оригинального проэмия жития, где Никита постулирует тезис о том, что составление душеполезных историй - это занятие, достойное действительно благородных мужей, которые должны быть за это прославляемы.

Еще одно обращение к версии Метафраста полностью подтверждает наш предыдущий вывод. Дело в том, что если само повествование в версии Симеона оставлено почти без изменений, то проэмий и заключение он переписал полностью. Что касается мысли Никиты о восхвалении благородных мужей писателей, то от нее у Симеона не осталось и следа. Подобное же изменение мы наблюдаем и в эпилоге. Метафраст убирает все, что касается личности агиографа, высказывая только традиционную идею о том, что провидение являет себя через чудесное,

\footnotetext{
${ }^{18}$ Vita... P. 227.

${ }^{19}$ Ibid. P. 231-232.
} 


\section{Светский чиновник как агиографр}

чем полностью переносит читателя в сферу божественного, в отличие от текста Никиты, где очень много земного.

\section{Автор и его произведение}

В заключение обратимся к внешней связи между автором и его литературным творением. Интересно поразмышлять, почему этот необыкновенно образованный человек, магистр, облеченный властью, знаток Античности, избрал именно такую тему и такой жанр. Представляется, что это очень важно для нашего понимания феномена агиографии в целом. Во-первых, мы должны вспомнить, что в самом начале рассказа, упоминая военные успехи адмирала Гимерия, Никита говорит, что это в равной степени достойная тема для литературного произведения, и он даже обещает вернуться к ней позже. Помимо стремления продемонстрировать читателю, что в данный момент времени он предпочитает тему божественного и чудесного, вероятно, его целью было убедить всех, что агиография так же нуждается в образованных авторах и изысканной литературной технике, как и иные жанры. Представляется, что это одна из граней взаимоотношения святых и власти, власти интеллекта и образованности. Она нужна для создания подобных произведений, поскольку нет сомнений, что святые и подвижники заслуживают прекрасных биографов не менее, чем светские персонажи. Никита Магистр демонстрирует, что житие может быть написано именно так, как это сделал он: с большой свободой, юмором, невероятной живостью характеров и элегантностью изложения. Он заявляет, что можно выпустить множество, казалось бы, наиважнейших деталей, как то большая часть биографии святой, включая даже и дату смерти, зато можно представить всю историю очень изысканной и приятной для чтения, надеясь при этом получить за свой труд ожидаемое вознаграждение.

\section{REFERENCES}

Flusin, B. (1993). L'Hagiographie monastique à Byzance au IXe et au Xe siècle. Revue Bénédictine, 103, 31-50.

Høgel, C. (2018). Beauty, Knowledge and Gain in the Life of Theoktiste. Byzantion, 88, 219-236.

Jazdzewska, K. (2009). Hagiographic Invention and Imitation: Niketas' Life of Theoktiste and Its Literary Models. Greek, Roman, and Byzantine Studies, 49, 257-279.

Kazhdan, A. (1985). Hagiographical Notes 9. The Hunter or the Harlot. Byzantinische Zeitschrift, 78, 49-55.

Niketas. Personenkennziffer 25740 (2013). In R.-J. Lilie, C. Ludwig, T. Pratsch, \& B. Zielke (Eds.), Prosopographie der mittelbyzantinischen Zeit. Berlin; Boston: de Gruyter. 
Ю. Б. Мантова

Nilsson, I. (2010). The Same Story, but Another. A Reappraisal of Literary Imitation in Byzantium. In A. Rhoby, \& E. Schiffer (Eds.), Imitatio - Aemulatio - Variatio. Akten des internationalen wissenschaftlichen Symposions zur byzantinischen Sprache und Literatur (pp. 195-208). Wien: Verlag der Österreichischen Academie der Wissenshaften.

Vita S. Theoctistae de insula Lesbo (1925, November). Acta Sanctorum, 4, 224-233.

Westerink, L. G. (1973). Nicétas Magistros. Lettres d'un exilé (928-946) (Le Monde Byzantin). Paris: Centre Nacional de la Recherche Scientifique.

\section{Мантова Юлия Борисовна}

кандидат филологических наук, преподаватель

кафедра византийской

и новогреческой филологии

Московский государственный

университет им. М. В. Ломоносова 119991, Москва, Ленинские горы, 1

E-mail: july8@mail.ru

\section{Mantova, Yulia Borisovna}

$\mathrm{PhD}$ (Philology), Lecturer

Byzantine and Modern Greek Philology

Department

M. V. Lomonosov Moscow State

University

1 Leninskiye Gory, Moscow, 119991,

Russia

E-mail: july8@mail.ru

ORCID: 0000-0002-3002-9942 